\title{
Electrokinetic remediation for smelting sludge containing heavy metals: a novel method on pH control of catholyte*
}

\author{
Yan-Ping Hu, Zhong-Guang Ji, Wei Wang, Li-Mei Yang and Zheng Xu \\ National Engineering Laboratory of Biohydrometallurgy, \\ General Research Institute for Nonferrous Metals, \\ Beijing, 100088, China \\ E-mail address:xzh63@126.com
}

\begin{abstract}
Electrokinetic remediation is an efficient and environmental friendly in-situ remediation technology for fine-grained soil or sludge. However, the problem of focusing phenomena caused by the $\mathrm{pH}$ values of sludge which controlled by the $\mathrm{pH}$ values of catholyte and polarization caused by the $\mathrm{pH}$ values of catholyte during electrokinetic process reduce the removal efficiency of heavy metals. In this work, an electrochemical method was designed, which was safety and environmental friendly to control the $\mathrm{pH}$ values of catholyte. The results of two experiments carried out five days under the constant voltage of $32 \mathrm{~V}$ have shown that the removal rate of heavy metals of $\mathrm{Cu}, \mathrm{Ni}, \mathrm{Pb}, \mathrm{Cr}$ and $\mathrm{Zn}$ in sludge is $15.63 \%, 15.65 \%, 9.35 \%, 42.86 \%, 8.35 \%$ when catholyte $\mathrm{pH}$ values controlled which is much better than $\mathrm{pH}$ uncontrolled $11.37 \%, 4.91 \%, 1.45 \%, 0 \%, 0 \%$ respectively. It was proved that focusing phenomena and polarization during electrokinetic process could be controlled.
\end{abstract}

Keywords: Electrokinetic Remediation; Smelting Sludge; Heavy Metals; pH Control of Catholyte.

\section{Introduction}

Rapidly increasing amount of domestic wastewater and industrial wastewater has led to the explosion of sludges output with the development of urbanization and industrialization in China. Nowadays, sludge disposal is mainly at the level of incineration, landfill, agriculture and material at home and abroad[1-4]. As a result of our ever-improving quality and lack of environment awareness in past, millions of tons of hazardous waste are generated every year. Many remediation technologies such as chemical remediation[5] phytoremediation[6], bioremediation[7] and electrokinetic remediation[8] have been developed to restore the damaged environment and ecology to protect the public health.

\footnotetext{
${ }^{*}$ This work is supported by International Cooperation Project: Research and development of a new combined technology based on membrane distillation and synergistic extraction for heavy metalsrich metallurgy wastewater treatment (2014DFA90920)
} 
Among them, electrokinetic, is an efficient and environmental friendly insitu technology.

In the process of electrokinetic remediation, the contaminants are migrated by the combined mechanism of electromigration, eletroosmosis and electrophoresis under extra direct-current electric field. Current efficiency and heavy metal removal efficiency reduced when the phenomenon of focusing and polarization happened caused by the $\mathrm{OH}^{-}$ions, which is generated at cathode, migrate into the electric tank[9]. However, not only focusing and polarization, but also dissolution, precipitation, adsorption, desorption, even migration of heavy metals is related to $\mathrm{pH}$. The $\mathrm{pH}$ values of sludge is always controlled by electrolyte. Weak acid and buffer solutions are introduced to neutralize the $\mathrm{OH}^{-}$ ions generated at cathode during electrokinetic remediation process. These methods can always control the $\mathrm{pH}$ values of electrolyte and get high extraction efficiency. However, improper use of some acids and buffer solutions in the process may pose a health hazard or secondary pollution. Hence, in this work, a novel method on $\mathrm{pH}$ control of catholyte was designed which was safety, environmental friendly and controlled by adjusting the current intensity.

\section{Materials and Methods}

\subsection{Swedge sludge}

Swedge sludge was provided by the largest smelting wastewater treatment plants in China. Table 1 shows the content of main heavy metals in sludge and the basic properties of the sludge.

Table 1. The content of main heavy metal in sludge

\begin{tabular}{llll}
\hline Characteristics & Values & Metals & Contents(\%) \\
Moisture content/\% & 74.5 & $\mathrm{Cu}$ & 5.01 \\
Organics $(\%)$ & 9.52 & $\mathrm{Zn}$ & 6.89 \\
$\mathrm{pH}$ & 8.48 & $\mathrm{Ni}$ & 0.61 \\
$\mathrm{CEC}(\mathrm{meq} / \mathrm{g}$ dry sludge $)$ & 13.8 & $\mathrm{~Pb}$ & 0.68 \\
$\mathrm{EC}(\mathrm{ms} / \mathrm{cm})$ & 2.41 & $\mathrm{Cr}$ & 0.028 \\
\hline
\end{tabular}

The basic properties of this sludge are summarized in Table 1. The moisture content of sludge was $74.5 \%$. The organic content was $9.52 \%$, which was determined by the lost fraction at a temperature of $450^{\circ} \mathrm{C}$. The $\mathrm{pH}$ values of sludge was 8.48 , which measured by mixing $10.0 \mathrm{~g}$ dry sludge and $25 \mathrm{ml} 1.0 \mathrm{M}$ $\mathrm{KCl}$ for $1 \mathrm{~h}$ of contact time and then measured using a Radiometer $\mathrm{pH}$ electrode. The cation exchange capacity (CEC) was determined by the ammonium acetate method and the electric conductivity(EC) was determined by a EC meter(DDSJ- 
308F). The metal content in the sludge was measured by $\operatorname{ICP}(700$ series 725 ICP-DES).

\subsection{Electrokinetic experiments}

The particle size of the sludge sample which was almost less than $0.0308 \mathrm{~mm}$. it is considered that the smaller the particle size of the sludge, the greater the viscosity of sludge, the smaller the porosity of the sludge, the larger the cation exchange capacity (CEC) of the sludge. Similar to most remediation technologies, electrokinetic remediation can only remove mobile contaminants from sludge [15-16]. Contaminants can exist as sorbed species on sludge particle surfaces, solid species as precipitates, sorbed species on colloidal particulates suspended in sludge pore fluid or dissolved species in sludge pore fluid. Only sorbed species on colloidal particulates suspended in sludge pore fluid or dissolved species in sludge pore fluid can be removed by most remediation including electrokinetic remediation. However, fine-grained sludge againsts the ions desorbed from sludge particle surfaces and migrated from sludge pore fluid especially when the $\mathrm{pH}$ of sludge was unsuitable. Therefore, the $\mathrm{pH}$ values of catholyte is one of most important factors of electrokinetic remediation. Because the contaminants in sludge tend to keep in a mobile chemical state in the suitable $\mathrm{pH}$ of sludge pore solution which in favor of the migration of metal ions.

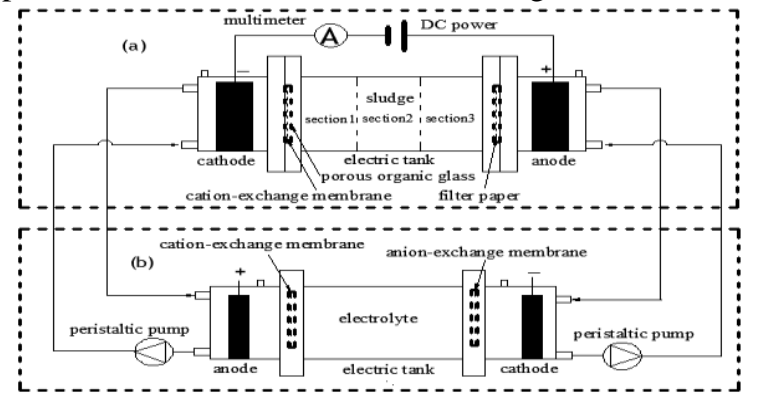

Fig. 1. The equipment connection diagram of electrokinetic remediation: (a) the EK equipment and (b) the $\mathrm{pH}$ control system (section 1, section 2 and section 3 followed in the article could be found in figure 1-(a))

The EK experiments were conducted in an organic glass cell (Figure 1-(a)) of $38 \mathrm{~cm}(\mathrm{~L}) \times 8 \mathrm{~cm}(\mathrm{~W}) \times 8 \mathrm{~cm}(\mathrm{H})$, consisting of cathode reservoir $(10 \mathrm{~cm}$ in length), electric tank (18cm in length) and anode reservoir(10 $\mathrm{cm}$ in length). Figure 1-(b) shows the $\mathrm{pH}$ control system of $28 \mathrm{~cm}(\mathrm{~L}) \times 8 \mathrm{~cm}(\mathrm{~W}) \times 8 \mathrm{~cm}(\mathrm{H})$. Other messages such as multimeter, DC power, peristaltic pump, graphite electrode can get from Figure 1.

Figure 2 shows the mechanism of the novel method on $\mathrm{pH}$ values control of catholyte. The mechanism of controlling the catholyte $\mathrm{pH}$ with electrochemical 
method is by adjusting the size of the input current which applied to the $\mathrm{pH}$ control system. And the size can be regulated through the adjustable slide rheostat or DC regulated power supply. As seen in Figure 2, the electrochemical device generated $\mathrm{H}^{+}$and $\mathrm{OH}^{-}$in the progress of electrolysis of electrolyte, then the generated $\mathrm{H}^{+}$and $\mathrm{OH}^{-}$neutralized the $\mathrm{OH}^{-}$and $\mathrm{H}^{+}$generated at the electrokinetic remediation device(Figure 1a) respectively, which electrolyte circulated by peristaltic pump. The cation-exchange membrane in Figure 2 is to prevent anions to enter electric tank and anion-membrane is to prevent cations to enter. The metal ions in the electrokinetic electrolyte, which overflowed from electrokinetic remediation device, could be concentrated at the electric tank of the $\mathrm{pH}$ control device by electro migration. Thus, it could accelerate the migration of metal ions and weak the concentration polarization and enhance the removal efficiency during electrokinetic process.

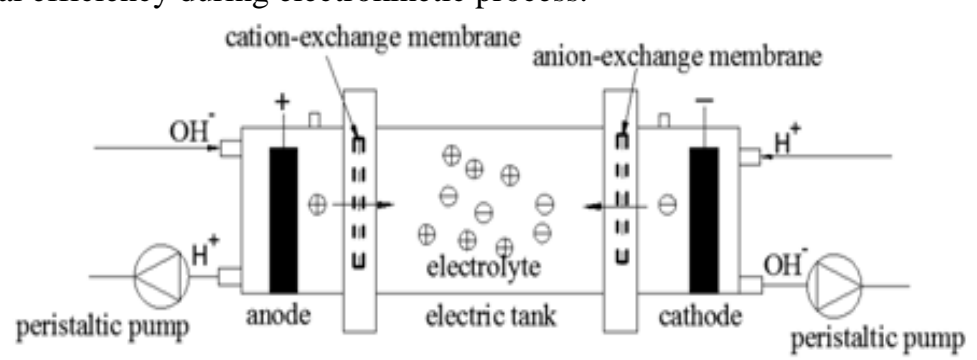

Fig. 2. The mechanism of controlling the $\mathrm{pH}$ by electrochemical method

Moreover, the ion exchange membrane of the $\mathrm{pH}$ control device can be cleaned and replaced anytime which operated simply and easy to install. The technology could solve the problem of the ions desorbed from sludge particle surfaces and migrated from sludge pore fluid led by the $\mathrm{pH}$ of pore fluid and the suitable $\mathrm{pH}$ which is important to some united technologies such as bioremediation combined with electrokinetic and agents, such as oxidizing agent, chelating agent, complexing agent.

For each test, $600 \mathrm{~mL}$ of sludge with $80 \%$ moisture was added into electrolytic tank. Then, the sludge was equilibrated for 24 hours to balance osmotic pressure. According to reference [17], the ideal potential gradient of electrokinetic remediation is $1 \sim 2 \mathrm{~V} / \mathrm{cm}$. Therefore, the treatments which $\mathrm{pH}$ of catholye was controlled and uncontrolled were conducted under a constant potential of $32 \mathrm{~V}$ for $5 \mathrm{~d}$ with $0.05 \mathrm{M}$ citric acid, $0.01 \mathrm{M}$ HNO3 as anolyte and catholyte respectively.

The sludge $\mathrm{pH}$ and sludge electric conductivity were monitored by $\mathrm{pH}$ and EC meter, respectively. The temperature of each section sludge and the current were measured by thermometer and multimeter during the experiment every day respectively. At the end of EK experiment, the representative sludge taken from 
each section was dissolved with acid and then analyzed by ICP (700 series 725 ICP-DES).

\section{Results and Discussion}

\subsection{Change of sludge $\mathrm{pH}$ and catholyte $\mathrm{pH}$}

Focusing phenomena and polarization during electrokinetic process were related to the $\mathrm{pH}$ of catholyte. Due to electrolytic decomposition of electrolytes at the electrodes, the $\mathrm{H}^{+}$and $\mathrm{OH}^{-}$are generated at the anode and cathode, respectively; And then migrated into sludge by the direct-current electric field imposed on the sludge, result in changes of $\mathrm{pH}$ values in sludge as a function of time and space[18]. Therefore, different techniques have been developed to condition the electrode reservoir solution. In this work, the $\mathrm{pH}$ of catholyte was controlled with electrochemical method.

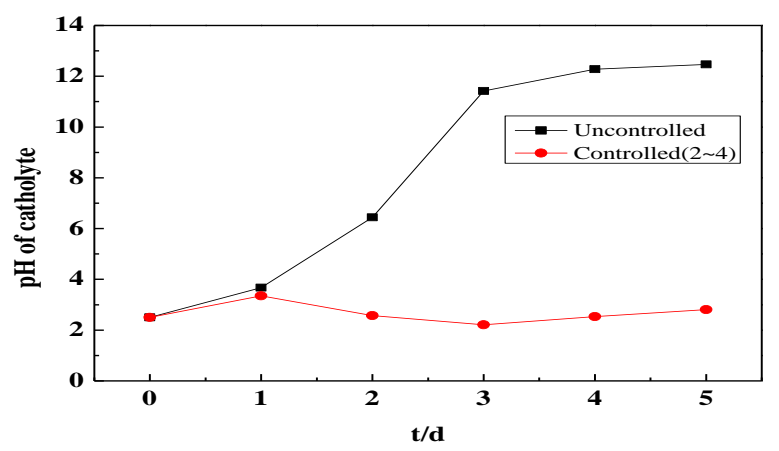

Fig. 3. Catholyte $\mathrm{pH}$ values versus treatment time

Figure 3 shows that the $\mathrm{pH}$ values of catholyte raised to 12 which $\mathrm{pH}$ values of catholyte was uncontrolled and the $\mathrm{pH}$ values of catholyte varied from 2 and 4 when controlled. The phenomenon of focusing and polarization happened in the treatment which $\mathrm{pH}$ values of catholyte was uncontrolled, while vanished or weakened when controlled.

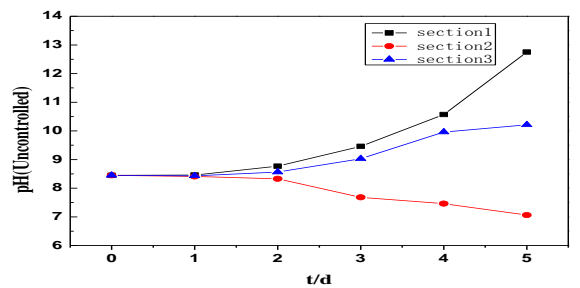

(a)

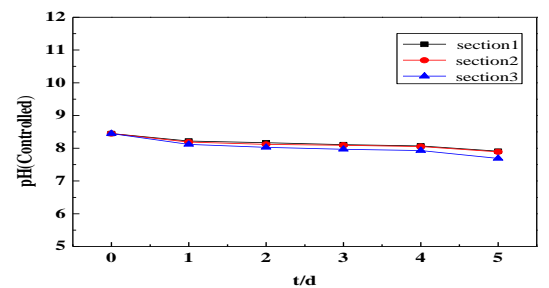

(b)

Fig. 4. The $\mathrm{pH}$ values of section versus treatment time: (a) the $\mathrm{pHs}$ of catholyte uncontrolled and (b)controlled 
Figure 4(a) which $\mathrm{pH}$ values of catholyte was uncontrolled shows that the $\mathrm{pH}$ of section 1 and section 2 in sludge raised whereas reduced at section 3 . And the focusing phenomenon exactly happened where the $\mathrm{pH}$ values of sludge raised or the $\mathrm{pH}$ values changed rapidly. Figure 4(b) which $\mathrm{pH}$ values of catholyte was controlled shows the $\mathrm{pH}$ values of sections in sludge decreased slightly as treatment time goes on for the high acid/base buffer capacity of sludge. Without a doubt the focusing phenomenon vanished when the $\mathrm{pH}$ values was controlled.

In a word, the focusing phenomena which happened in electric tank close to cathode and the polarization phenomena which catholyte changed from clarify to turbidity, graphite electrode covered with precipitate discovered or weaken when the $\mathrm{pH}$ values of catholyte was controlled. That is to say the $\mathrm{pH}$ values of catholyte and sludge could be controlled by this electrochemical method and then phenomenon of focusing and polarization could be weakened by controlling $\mathrm{pH}$ values.

\subsection{Change of electric current and temperature}

Figure 5 shows the results of current density as a function of time.

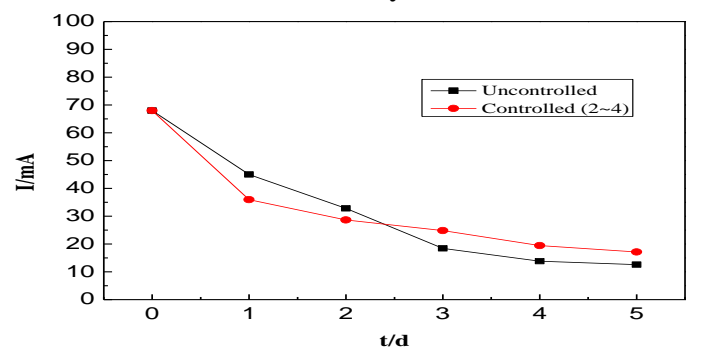

Fig. 5. Current density versus treatment time

From Figure 5, the current density was high for each test at the beginning of the test and it decreased after. After 2-day treatment, the current density which $\mathrm{pH}$ values of catholyte was controlled decreased to a stable range of 15-25 mA and maintained for the rest of the operation time. While the current density which $\mathrm{pH}$ values of catholyte was uncontrolled decreased to a stable range of 10-20 $\mathrm{mA}$ after 3-day and maintained for the rest of the treatment time. In general, the current density is related to concentrations of metals ion in sludge pore solution. Therefore, the migration efficiency of metal ions reduced so as to the ions stayed in the sludge pores solution before the 2-days when the $\mathrm{pH}$ values of catholyte was uncontrolled. As sludge pores was clogged when focusing phenomena happened and voltage efficiency was reduced when polarization phenomena happened during the treatment. While the current density of the treatment which $\mathrm{pH}$ values was uncontrolled was lower than 
which controlled is because the phenomenon of focusing and polarization got worse after 3 days which magnified the circuitous resistance.

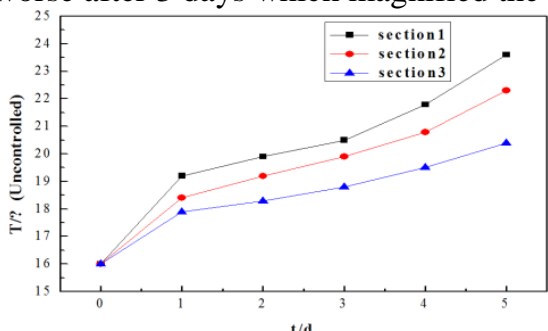

(a)

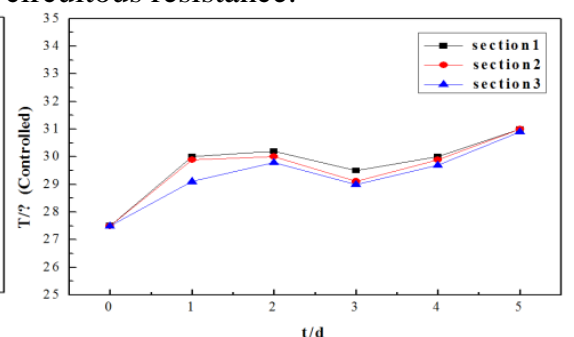

(b)

Fig. 6. The temperature of section versus treatment time

Figure 6 shows the temperature of each section with time. The tendency of section $1>\operatorname{section} 2>\operatorname{section} 3$ wasn't changed all the treatment time. The temperature of each section of the treatment which $\mathrm{pH}$ values of catholyte was uncontrolled (Figure 6(a)) increased obviously within the scope of $8^{\circ} \mathrm{C}$ with treatment time. However, Figure 6(b) shows the scope of the temperature of each section changed slowly within $4^{\circ} \mathrm{C}$ with treatment time and the temperature gap of each section was smaller than the treatment which $\mathrm{pH}$ values of catholyte was uncontrolled. The temperature of each section changed due to the problem of the electrical conductivity of sludge solution. Low concentration ions and focusing phenomena happened in electric tank reduced the electrical conductivity of sludge solution, increased the regional resistance of sludge. According to principle of Joule, the larger the regional resistance of sludge was, the more heat the sludge gotten and the higher the temperature increased.

\subsection{Removal of heavy metals from sludge}

The removal rate of heavy metals from sludge was influenced by the basic properties of the sludge and experiment condition. While controlling the $\mathrm{pH}$ values of sludge, which controlled by electrolyte, is particularly important for the success of electrokinetic. Since the $\mathrm{pH}$ values, which changed in sludge, could change the states of metal ions, hinder the mobile of metal ions. When the magnitude and the direction of electroosmotic flow was changed, then the transport of ions in sludge pore fluid by electroosmotic was changed also. Moreover, these ions can polarize the electrodes, reduce the voltage efficiency and the removal rate of heavy metals. The removal rate of heavy metals in sludge was listed in Table 2 . 
Table 2 . The removal rate of heavy metals in sludge (\%)

\begin{tabular}{llllll}
\hline Treatments & $\mathrm{Cu}$ & $\mathrm{Ni}$ & $\mathrm{Pb}$ & $\mathrm{Cr}$ & $\mathrm{Zn}$ \\
\cline { 2 - 6 } Uncontrolled & 11.37 & 4.91 & 1.45 & 0 & 0 \\
Controlled(2 4) & 15.63 & 15.65 & 9.35 & 42.86 & 8.35 \\
\hline
\end{tabular}

As seen in Table 2, the removal efficiency of $\mathrm{Cu}, \mathrm{Ni}, \mathrm{Pb}, \mathrm{Cr}$ and $\mathrm{Zn}$ from $11.37 \%, 4.91 \%, 0 \%, 0 \%$ and $0 \%$ in the treatment which $\mathrm{pH}$ values of catholyte was uncontrolled increased to $15.63 \%, 15.65 \%, 9.35 \%, 42.86 \%$ and $9.35 \%$ when controlled. The removal rate of $\mathrm{Ni}, \mathrm{Pb}, \mathrm{Cr}$ and $\mathrm{Zn}$ enhanced obviously, especially the removal rate of $\mathrm{Cr}$. Therefore, the treatment results show that the removal efficiency of metals in the sludge could improve by controlling the $\mathrm{pH}$ values of catholyte by electrochemical method.

\section{Conclusions}

With the experimental results of heavy metal removal from smelting water sludge by $\mathrm{pH}$ values controlled and uncontrolled systems, the conclusions have been draw as follows:

(1) The $\mathrm{pH}$ control system could control the $\mathrm{pH}$ values of catholyte and sludge pore fluid.

(2) The $\mathrm{pH}$ values control of catholyte could weak the focusing phenomena and polarization generated during electrokinetic process.

(3) The $\mathrm{pH}$ control of catholyte could improve the removal efficiency of metals in the sludge. The removal efficiency of heavy metals in sludge which are $\mathrm{pH}$ values of catholyte controlled by the electrochemical method and not controlled, were $\mathrm{Cu} 15.63 \%$, Ni15.65\%, $\mathrm{Pb} 9.35 \%, \mathrm{Cr} 42.86 \%$ and $\mathrm{Zn} 8.35 \%$ and $\mathrm{Cu} 11.37 \%$, Ni4.91\%, $\mathrm{Pb} 1.45 \%, \mathrm{Zn} 0 \%$, Cr0\%,respectively. The removal efficiency of $\mathrm{Ni}, \mathrm{Pb}, \mathrm{Cr}$ and $\mathrm{Zn}$ enhanced obviously, especially the removal rate of $\mathrm{Cr}$.

The result would be better if the $\mathrm{pH}$ of sludge reduced, enhancement agents introduced or other technologies added in electrokinetic remediation.

\section{References}

1. R.D. MacNicol, P.H.T. Beckett, The distribution of heavy metal between the principal components of digested sewage sludge, J. Water Research. 1989.

2. X.D. Cai, X.Q. Liu, The development and disposal of waster water sludge, J. Environmental Sanitation Engineering. 02(1994) 18-21.

3. N.N. Tian, K.J. Wang, L.P. Yang, The sludge disposal and utilization way of Sewage treatment plant, J. environmental protection. 02(2000) 18-20. 
4. G.R. Xu, J.L. Zou, G.B. Li, Stabilization of heavy metals in sludge ceramsite, J. Water research. 44(2010) 2930-2938.

5. M. Farrell, W.T. Perkins, P.J. Hobbs, G.W. Griffith, D.L. Jones, Migration of heavy metals in soil as influenced by compost amendments, J. Environmental Pollution. 158(2010) 55-64.

6. X.H. Zhao, W.F. Ma, J.M. Sun, Phytoremediation of Heavy Metal-Organic Complex in Dredged Sewage River Sediment, J. Journal of Tianjin university. 38(2005) 1011-1016.

7. Sh.G. Zhou, L.X. Zhou, H.Z. Huang, Removal of Heavy Metals From Sewage Sludge by Bioleaching, J. Acta Ecological Sinica. 22(2002) 125133.

8. M.M. Page, C. L. Page, Electroremediation of contaminated soils, J. Journal of Environmental Engineering, 128(2002) 208-219.

9. A.T. Yeung, Electrokinetic flow process in porous media and their applications, J. Journal of Hazardous Materials, 2(1994) 309-395. 